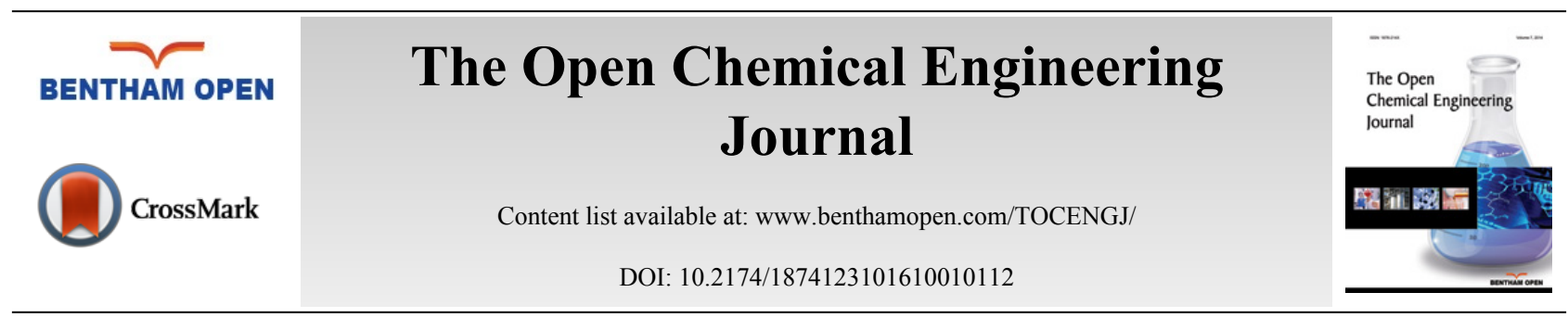

RETRACTION

\title{
Retraction Notice: The Research of the Mineralogical and Element Geochemical Characteristics of Bauxite in Yunfeng, Qingzhen, in Central Guizhou Province, China
}

\author{
Yang $\mathrm{Wu}^{*}$, Dai Tagen and Long Yongzhen \\ School of Geosciences and Info-Physics, Central South University, Hunan Changsha, 410083, P.R. China
}

\section{RETRACTION}

The Publisher and Editor have retracted this article [1] in accordance with good ethical practices. After a thorough investigations we believe that the peer review process was compromised. The article was published on-line on 22-10-2015.

\section{REFERENCE}

[1] Y. Wu, D. Tagen, and L. Yongzhen, "The Research of the Mineralogical and Element Geochemical Characteristics of Bauxite in Yunfeng, Qingzhen, in Central Guizhou Province, China", Open. Chem. Eng. J., vol. 9, pp. 134-142, 2015.

(C) Guoqing et al.; Licensee Bentham Open.

This is an open access article licensed under the terms of the Creative Commons Attribution-Non-Commercial 4.0 International Public License (CC BY-NC 4.0) (https://creativecommons.org/licenses/by-nc/4.0/legalcode), which permits unrestricted, non-commercial use, distribution and reproduction in any medium, provided the work is properly cited.

\footnotetext{
* Address correspondence to this author at the School of Geosciences and Info-Physics, Central South University, Hunan Changsha, 410083, P.R. China; E-mail: 774762582@qq.com
} 